\title{
Usefulness of different techniques for measuring body composition changes during weight loss in overweight and obese women
}

\author{
Cláudia S. Minderico ${ }^{1}$, Analiza M. Silva ${ }^{1}$, Kathleen Keller $^{2}$, Teresa L. Branco ${ }^{1}$, Sandra S. Martins ${ }^{1}$, \\ António L. Palmeira ${ }^{1}$, José T. Barata ${ }^{1}$, Elvis A. Carnero ${ }^{1}$, Paulo M. Rocha ${ }^{1}$, Pedro J. Teixeira ${ }^{1}$ and \\ Luís B. Sardinha ${ }^{1 *}$ \\ ${ }^{1}$ Exercise and Health Laboratory, Faculty of Human Movement, Technical University of Lisbon, Estrada da Costa, 1499-688 \\ Cruz-Quebrada, Portugal \\ ${ }^{2}$ New York Obesity Research Center, St Luke's-Roosevelt Hospital, Columbia University Institute of Human Nutrition, College of \\ Physicians and Surgeons, New York, NY, USA
}

(Received 25 August 2006 - Revised 19 June 2007 - Accepted 19 June 2007)

The objective was to compare measures from dual-energy X-ray absorptiometry (DXA), bioelectrical impedance analysis (BIA) and anthropometry with a reference four-compartment model to estimate fat mass (FM) and fat-free mass (FFM) changes in overweight and obese women after a weight-loss programme. Forty-eight women (age $39.8 \pm 5.8$ years; weight $79.2 \pm 11.8 \mathrm{~kg}$; BMI $30.7 \pm 3.6 \mathrm{~kg} / \mathrm{m}^{2}$ ) were studied in an out-patient weight-loss programme, before and after the 16-month intervention. Women attended weekly meetings for the first 4 months, followed by monthly meetings from 4 to 12 months. Body composition variables were measured by the following techniques: DXA, anthropometry (waist circumference-based model; Antrform), BIA using Tanita (TBF-310) and Omron (BF300) and a reference four-compartment model. Body weight decreased significantly ( -3.3 (SD 3.1) kg) across the intervention. At baseline and after the intervention, FM, percentage FM and FFM assessed by Antrform, Tanita, BF300 and DXA differed significantly from the reference method $(P \leq 0.001)$, with the exception of FFM assessed by Tanita (baseline $P=0.071$ and after $P=0.007)$. DXA significantly overestimated the change in FM and percentage FM across weight loss $(-4.5 v$. $-3.3 \mathrm{~kg} ; P<0.001$ and -3.7 v. $-2.0 \% ; P<0.001$, respectively), while Antrform underestimated FM and percentage FM $(-2.8 v .-3.3 \mathrm{~kg}$; $P=0.043$ and -1.1 v. $-2.0 \% ; P=0.013)$ compared with the four-compartment model. Tanita and BF300 did not differ $(P>0.05)$ from the reference model in any body composition variables. We conclude that these methods are widely used in clinical settings, but should not be applied interchangeably to detect changes in body composition. Furthermore, the several clinical methods were not accurate enough for tracking body composition changes in overweight and obese premenopausal women after a weight-loss programme.

Body composition: Weight loss: Intervention studies

The accurate measurement of body composition is crucial to understanding the impacts of different types of weight-loss interventions on body compartments. Although impressive advances have been made in the techniques available for measuring human body composition, due to cost and limited availability, use in clinical practice has been limited. The most common methods for estimating body composition changes that are available to clinicians include dual-energy X-ray absorptiometry (DXA), bioelectrical impedance analysis (BIA), anthropometry and, the most widely applied, BMI.

At the simplest level, techniques for measuring body composition can assume that the body is divided into two compartments, fat mass (FM) and fat-free mass (FFM). The fat component is of relatively homogeneous composition, but FFM consists of a heterogeneous mix of water, mineral, protein and additional minor constituents ${ }^{1,2}$. In order to quantify the amount of FM and FFM, using a two-compartment model, one must assume that these components exist in a known relationship to each other. For example, hydrodensitometry, or underwater weighing, assumes known densities of FM and FFM. By measuring the mass and volume of a subject, one could estimate the amount of FM and FFM, based on the assumed densities of these compartments. In clinical practice, however, there is considerable inter-individual variability in the density of FM and FFM that can affect the accuracy of this measure ${ }^{1,2}$. There are even within-subject differences, particularly in the proportion of water and mineral in $\mathrm{FFM}^{2}$. This variability contributes to the absolute error of this method.

Because of the changes in FFM and total body composition that can occur during a weight-loss programme, multi-compartment models have been developed in which various components of the body are independently measured, thus reducing the error involved with body composition measurement $^{3}$. An early example of this approach was that of $\mathrm{Siri}^{4}$ who divided the body into a three-compartment model comprising of fat, water, and a 'fat-free dry substance'

Abbreviations: BIA, bioelectrical impedance analysis; BIA-BF300, BIA using Omron BF300; BIA-Tanita, BIA using Tanita TBF-310; BV, body volume; DFFM, density of FFM; DXA, dual-energy X-ray absorptiometry; FM, fat mass; FFM, fat-free mass; TBW, total body water; TEM, technical error of measurement.

* Corresponding author: Dr Luís Bettencourt Sardinha, fax +35 12141491 93, email lsardinha@fmh.utl.pt 
(protein plus mineral). Moreover, four-compartment models, that also take into account the measurement of body mineral, can further reduce the variability in the density of FFM ( $\left.D_{\text {FFM }}\right)$ measurement. One of the primary advantages of the four-compartment model is that it provides a more accurate measure of body composition than do other methods, particularly because it requires fewer assumptions than three- and two-compartment models ${ }^{5}$. Despite their apparent advantages, few studies have used four-compartment models to evaluate changes in body composition that result during weight loss 6 .

Any changes in the assumed constants induce inaccurate FM assessment when two-compartment models are used. This may be the case when measuring body composition in obese patients, as changes in the $D_{\mathrm{FFM}}$ were observed due to an increased hydration of $\mathrm{FFM}^{7}$. Within the scope of weight loss this methodological issue assumes further importance for the use of a reference four-compartment model, because it is plausible that FFM composition may differ from the assumed constants in the two-compartment model and may change from subject to subject.

In addition to the aforementioned applications in a research setting, clinicians might also benefit from the use of four-compartment models in clinical diagnosis and patient care when accurate estimates are desired. However, these estimates are costly and time consuming, highlighting a need to identify alternative methods that are convenient, reliable and accurate for measuring changes in body composition that occur with weight loss. Only three studies have assessed the validity of different body composition measures in overweight and obese populations by making comparisons with a reference four-compartment molecular model ${ }^{6,8,9}$. However, none of these studies used a long-term weight-loss programme in women with a wide range of fatness change. Therefore, the aim of the present study was to compare measures from DXA, BIA and anthropometry with a reference four-component molecular model to estimate FM and FFM changes in overweight and obese women after a weight-loss management programme.

\section{Experimental methods}

Subjects

Participants were recruited from a community sample for a 2-year weight-management programme through newspaper advertisements, the Internet and announcement flyers. Only females were eligible to participate in the study. The other inclusion criteria were age $>24$ years, premenopausal and not currently pregnant, BMI $>24.9 \mathrm{~kg} / \mathrm{m}^{2}$, healthy and not currently taking medications. After one orientation session, 152 women signed up for the programme. During the run-in phase, four women decided not to participate (reporting new time and scheduling conflicts), four did not comply with testing requirements and were excluded, three women found out they were pregnant or decided to attempt pregnancy and were also excluded, and one subject was found ineligible due to medical reasons (untreated hyperthyroidism), leaving a total of 140 women who started the intervention. An initial visit with the study physician ensured that subjects met all medical inclusion criteria. Participants agreed to refrain from participating in any other weight-loss programme and gave written informed consent before participation in the study. The Institutional Review Board of the Faculty of Human Movement, Technical University of Lisbon, approved the study, described elsewhere ${ }^{10}$.

At 1 year after the intervention, ninety-three women were evaluated but only forty-eight women performed all the body composition methods and lost weight.

\section{Body composition measurements}

Measurements of body composition using each technique were conducted according to standard procedures. Subjects came to the laboratory, after a $12 \mathrm{~h}$ fast, and $24 \mathrm{~h}$ without exercise, alcohol or stimulant beverages. All measurements were carried out in the same morning. In brief, the procedures were as follows.

Anthropometry. Subjects were weighed to the nearest $0.01 \mathrm{~kg}$ wearing a bathing suit and without shoes on an electronic scale connected to the plethysmograph computer $\left(\right.$ BOD POD $^{\circledR}$; Life Measurement, Inc., Concord, CA, USA). Height was measured to the nearest $0.1 \mathrm{~cm}$ with a stadiometer (Seca, Hamburg, Germany).

The Weltman et al. ${ }^{11}$ formula was used to estimate percentage FM, as this model was developed for obese subjects. The equation is described as follows:

Percentage $\mathrm{FM}=0.11077 \times \mathrm{ABCirc}-0.17666 \times \mathrm{Ht}$

$$
+0.14354 \times \mathrm{Wt}+51.03301,
$$

where $\mathrm{ABCirc}$ is the mean abdominal circumference $((\mathrm{AB} 1+\mathrm{AB} 2) / 2 ; \quad \mathrm{AB} 1$ is the abdominal circumference measured between the appendix xifoid and the umbilical level and AB2 is measured at the umbilical level), $\mathrm{Ht}$ is height $(\mathrm{cm})$ and $\mathrm{Wt}$ is body weight $(\mathrm{kg})$.

A trained researcher performed the circumference measurements according to the standardised procedures described elsewhere ${ }^{12}$. Based on ten repetitions, the technical error of measurement (TEM) and intraclass coefficient of correlation were $0.37 \mathrm{~cm}$ and 1.00 for $\mathrm{AB} 1$ and $0.62 \mathrm{~cm}$ and 1.00 for $\mathrm{AB} 2$, respectively.

Bioelectrical impedance analysis. BIA from foot to foot was measured using the Tanita body composition analyser (model TBF-310; Tanita Corp., Tokyo, Japan), which provides a print-out of measured impedance and calculated body fat. Subjects were measured without shoes, and in bathing suits. BIA from hand to hand was measured using the Omron BF300 (Omron Corp., Kyoto, Japan), which provides absolute and percentage body fat.

Dual-energy X-ray absorptiometry. To estimate FM and FFM, DXA measurements were made with a total body scanner (QDR-1500, pencil-beam mode, software version 5.67 enhanced whole-body analyses; Hologic, Waltham, MA, USA) that measured the attenuation of X-rays pulsed between 70 and $140 \mathrm{kV}$ synchronously with the line frequency for each pixel of the scanned image. Following the protocol for DXA described by the manufacturer, a step phantom with six fields of acrylic and aluminium of varying thickness and known absorptive properties was scanned alongside each subject to serve as an external standard for the analysis of different tissue components. The same laboratory technician positioned the subjects, performed the scans and executed 
the analysis according to the operator's manual using the standard analysis protocol. Based on ten subjects, the CV in our laboratory for FM and FFM were 2.9 and $1.7 \%$, respectively.

Four-compartment model. The four-compartment model developed by Heymsfield et al. ${ }^{5}$ was used as the reference method. Accordingly, FM was assessed with the following equation:

$$
\begin{aligned}
\mathrm{FM}(\mathrm{kg})= & ((2.513 \times \mathrm{BV})-(0.739 \times \mathrm{TBW})) \\
& +((0.947 \times \mathrm{Mo})-(1.79 \times \mathrm{BW})),
\end{aligned}
$$

where BV is body volume (litres), TBW is total body water $(\mathrm{kg})$, Mo is bone mineral $(\mathrm{kg})$ and $\mathrm{BW}$ is body weight $(\mathrm{kg})$.

\section{Calculation of density of fat-free mass}

The $\mathrm{D}_{\mathrm{FFM}}$ was estimated from TBW, bone mineral (Mo) and residual (residual is equal to body mass minus FM from the four-compartment model, TBW and bone mineral) contents of FFM (estimated as body mass minus FM from the fourcompartment model) and densities of TBW $\left(\mathrm{D}_{\mathrm{TBW}}\right)$, bone mineral $\left(\mathrm{D}_{\mathrm{Mo}}\right)$ and residual $\left(\mathrm{D}_{\text {residual }}\right) ; 0.99371,2.982$ and $1.404 \mathrm{~g} / \mathrm{cm}^{3}$, respectively:

$$
\begin{aligned}
\mathrm{D}_{\mathrm{FFM}}= & 1 /\left(\left(\mathrm{TBW} / \mathrm{D}_{\mathrm{TBW}}\right)+\left(\mathrm{Mo} / \mathrm{D}_{\mathrm{Mo}}\right)\right. \\
& \left.+\left(\text { residual } / \mathrm{D}_{\text {residual }}\right)\right) .
\end{aligned}
$$

\section{Body volume}

BV was assessed by air-displacement plethysmograph (BOD POD $^{\circledR}$; Life Measurement, Inc., Concord, CA, USA). The use of this method is described in detail elsewhere ${ }^{13,14}$. Briefly, after voiding the bladder, each subject was weighed to the nearest $g$ while wearing a swimsuit. The BOD POD ${ }^{\circledR}$ was calibrated according to the manufacturer's instructions, and raw BV was determined. The effects of clothing and hair are accounted for by using minimal clothing, such as a bathing suit, and by compressing hair with a swimming cap. Finally, thoracic gas volume was measured in the BOD POD $^{\circledR}$ by using a technique, common to standard pulmonary plethysmography, called the 'panting manoeuvre" 15 . While wearing a noseclip, the subjects breathed through a tube; after two to three normal breaths, the airway was occluded for $3 \mathrm{~s}$ at mid-exhalation. During this time, the subject was instructed to gently puff against the occlusion by alternately contracting and relaxing the diaphragm.

All measurements were conducted with the BOD POD ${ }^{\circledR}$ software version 1.68 (Life Measurement, Inc.).

Based on ten repetitions, TEM and the $\mathrm{CV}$ for BV were 0.2 litres and $0.5 \%$, respectively.

\section{Total body water}

An accurate method to estimate TBW is by bioelectrical impedance spectroscopy analysis (model 4000B; Xitron Technologies, San Diego, CA, USA). Before the test, subjects were instructed to lie in a supine position with their arms and legs abducted at a $45^{\circ}$ angle for $10 \mathrm{~min}$. This impedance spectra was modelled with the Cole-Cole cell suspension model ${ }^{16}$ to derive a theoretical impedance at zero and infinity frequency, based on a non-linear curve fitting from the measured resistance and reactance. Intracellular water and extracellular water were predicted from the Hanai mixture theory ${ }^{17}$, and TBW was estimated by the sum of intracellular water and extracellular water. Considering ten repeated measures, the TEM and CV for TBW were 0.47 litres and $1.1 \%$ respectively.

\section{Bone mineral}

Total body bone mineral was measured using DXA (QDR1500, pencil-beam mode, software version 5.67 enhanced whole-body analyses; Hologic, Waltham, MA, USA) as described earlier for FM and FFM. Considering that bone mineral content represents ashed bone, bone mineral content was converted to total body bone mineral by multiplying it by 1.0436 (Ballor $1996^{18}$ ). The TEM and CV for bone mineral content in our laboratory were $0.02 \mathrm{~kg}$ and $1.6 \%$, respectively.

\section{Propagation measurement error}

In the present study we selected air-displacement plethysmography to assess BV, DXA to estimate bone mineral, and BIA to estimate TBW. The propagation of measurement errors associated with the determination of $\mathrm{BV}, \mathrm{TBW}$ and bone mineral (Mo) can be calculated by assuming that the squared technical errors of measurement $\left(\mathrm{TEM}^{2}\right)$ are independent and additive ${ }^{18}$. Accordingly:

$$
\begin{aligned}
\mathrm{TEM}= & \left(\mathrm{TEM}^{2}\right. \text { for effect of air } \\
& - \text { displacement plethysmography on } \% \mathrm{FM} \\
& +\mathrm{TEM}^{2} \text { for TBW } \% \mathrm{FM} \\
& \left.+\mathrm{TEM}^{2} \text { for Mo } \% \mathrm{FM}\right)^{0.5}
\end{aligned}
$$

So, using the above equation:

$$
\begin{aligned}
\text { TEM } & =\left(0 \cdot 81^{2}+0 \cdot 34^{2}+0 \cdot 04^{2}\right) 0 \cdot 5 \\
& =0.77 \% \mathrm{FM} \text { from TEM values. }
\end{aligned}
$$

From these calculations, the test-retest reliability in the present study was about $0.8 \%$ FM units.

\section{Statistical analysis}

Data were analysed with SPSS for Windows version 13.0 (SPSS Inc., Chicago, IL, USA). Descriptive statistics including mean values and standard deviations were calculated for all outcome measurements (age, weight, height, BV, FM, FFM, TBW, bone mineral, protein, density).

Simple linear regressions were performed to calculate the relationship between FM, percentage FM, and FFM estimated by the reference four-compartment model and DXA, BIA using Tanita TBF-310 (BIA-Tanita), BIA using Omron BF300 (BIA-BF300) and anthropometrics. Bias between methods was assessed with paired $t$ tests. Where differences were found between the test measures and the four-compartment model, linear regression models were developed to determine if the observed differences were explained by variation 
of $\mathrm{D}_{\mathrm{FFM}}$ and FFM hydration. Agreement between methods was assessed $^{19}$, including the $95 \%$ limits of agreement. The correlation between the mean of the reference method and the assessed method with difference between both was used as an indication of trend, i.e. the difference between the methods varied across fatness levels. Linear regressions were also performed to assess the relationships between initial body weight and the differences between FM, percentage FM and FFM changes estimated by the reference four-compartment model and DXA, BIA-Tanita, BIA-BF300 and anthropometrics. For all tests, statistical significance was set at $P<0 \cdot 05$.

\section{Results}

\section{Subjects' characteristics}

Baseline and after intervention. Mean values and standard deviations for the descriptive characteristics are summarised in Table 1. It is worth mentioning that after the intervention, $D_{\text {FFM }}$ was identical to the reference man $\left(1.1 \mathrm{~g} / \mathrm{cm}^{3}\right)$, even though all compartments of the FFM deviate from the reference man. There were no significant differences in bone mineral:FFM at baseline and after intervention ( $0 \cdot 1$ (SD 0.2) $\% ; P=0.096)$. All the other variables were significantly different $(P<0.05)$ after intervention.

The mean values and standard deviations at baseline, after intervention, and respective differences in FM, percentage FM and FFM by the indicated methods are summarised in Table 2 . When compared with the reference four-compartment model, FM, percentage FM, and FFM assessed by anthropometry (waist circumference-based model; Antrform), BIA-Tanita, BIA-BF300 and DXA were significantly different at baseline and after intervention $(P \leq 0.001)$, with the exception for FFM assessed by BIA-Tanita (baseline, $P=0.071$ and after, $P=0 \cdot 007$ ).

Changes. All body composition methods presented a significant $(P<0.05)$ decrease in FM and percentage FM after intervention. The largest decrease was obtained by DXA, which overestimated FM change $(-4.5 v .-3.3 \mathrm{~kg} ; P<0.001$ and
$-3.7 v .-2.0 \% ; P<0.001)$ when compared with the four-compartment model. Conversely, the Antrform method underestimated FM change $(-2.8 v .-3.3 \mathrm{~kg} ; P=0.043$ and $-1.1 v$. $-2.0 \% ; P=0.013)$. BIA-Tanita and BIA-BF300 did not differ $(P<0.05)$ from the reference multi-compartment model in any body composition variable.

\section{Accuracy of body composition changes}

The accuracy data of the Antroform, BIA-Tanita, BIA-BF300 and DXA methods to estimate FM, percentage FM and FFM changes are presented in Table 3 .

For FM and percentage FM all intercepts were not different from zero $(P<0 \cdot 05)$. A similar result was found for FFM using the Antrform method. For FM, only slopes calculated from the BIA methods were not different from $1(P>0.05)$, while for percentage FM only BIA-BF300 was not different from 1 $(P<0 \cdot 05)$. All slopes for FFM were different from $1(P<0 \cdot 05)$.

\section{Agreement analysis}

The agreement between the four-compartment model and the other methods is also indicated in Table 3. A significant bias was found between the four-compartment model and Antrform and DXA in all body composition variables. The $95 \%$ limits of agreement ranged from -3.4 to 4.5 for FM, from -5.7 to 5.4 for percentage FM, and from -3.8 to 4.4 for FFM. For FM and percentage FM, a significant trend was found for the Antrform method $(P<0.001)$, BIA-BF300 $(P=0.030)$ and DXA $(P=0.009)$, i.e. there was a correlation between the mean of each of these methods with the four-compartment model and the difference between both. Bland-Altman plots of absolute FM and FFM changes are shown in Fig. 1.

\section{Fat-free mass hydration and density}

The effect of FFM hydration and density on body composition differences was investigated to determine if it could explain

Table 1. Subject ( $n$ 48) characteristics and body composition (multi-compartment model) (Mean values and standard deviations)

\begin{tabular}{|c|c|c|c|c|c|c|}
\hline \multirow[b]{2}{*}{ Variables } & \multicolumn{2}{|c|}{ Baseline } & \multicolumn{2}{|c|}{ After intervention } & \multicolumn{2}{|c|}{ Difference } \\
\hline & Mean & SD & Mean & SD & Mean & SD \\
\hline Age (years) & $39 \cdot 8$ & $5 \cdot 8$ & - & - & - & - \\
\hline Height (cm) & $160 \cdot 4$ & $5 \cdot 8$ & - & - & - & - \\
\hline Weight (kg) & $79 \cdot 2$ & $11 \cdot 8$ & $74 \cdot 8$ & 11.9 & $-4 \cdot 4^{\star \star}$ & $3 \cdot 2$ \\
\hline BMI $\left(\mathrm{kg} / \mathrm{m}^{2}\right)$ & $30 \cdot 8$ & 3.5 & $29 \cdot 0$ & $3 \cdot 6$ & -1.8 & $1 \cdot 3$ \\
\hline BV (litres) & 78.9 & $12 \cdot 4$ & $74 \cdot 0$ & $12 \cdot 5$ & $-4 \cdot 9^{\star \star}$ & $3 \cdot 6$ \\
\hline $\mathrm{FM}(\mathrm{kg})$ & 32.9 & $8 \cdot 4$ & $29 \cdot 6$ & $8 \cdot 1$ & $-3 \cdot 3^{\star \star}$ & $3 \cdot 1$ \\
\hline FM (\%) & $41 \cdot 1$ & $5 \cdot 2$ & $39 \cdot 1$ & $5 \cdot 3$ & $-2 \cdot 0^{\star \star}$ & $2 \cdot 8$ \\
\hline FFM (kg) & $46 \cdot 3$ & $5 \cdot 0$ & $45 \cdot 2$ & $5 \cdot 3$ & $-1 \cdot 1^{\star \star}$ & 1.5 \\
\hline TBW (kg) & $35 \cdot 2$ & 3.9 & $33 \cdot 6$ & $447 \cdot 0$ & $-1 \cdot 6^{\star \star}$ & 1.9 \\
\hline TBW:FFM (\%) & $76 \cdot 2$ & $2 \cdot 2$ & 74.4 & $2 \cdot 2$ & $-1 \cdot 8^{\star \star}$ & 2.5 \\
\hline Mo $(k g) \dagger$ & $2 \cdot 7$ & 0.3 & $2 \cdot 6$ & 0.3 & $-0.1^{*}$ & 0.1 \\
\hline Mo:FFM (\%) & $5 \cdot 7$ & 0.5 & $5 \cdot 8$ & 0.5 & 0.1 & 0.2 \\
\hline Residual (kg) & 8.4 & 1.5 & 8.9 & $1 \cdot 1$ & $0.5^{\star}$ & $1 \cdot 1$ \\
\hline Residual:FFM (\%) & $18 \cdot 1$ & $2 \cdot 2$ & $19 \cdot 8$ & $2 \cdot 0$ & $1 \cdot 7^{\star \star}$ & 2.5 \\
\hline Density of FFM $\left(\mathrm{g} / \mathrm{cm}^{3}\right)$ & 1.093 & 0.008 & $1 \cdot 100$ & 0.009 & $0.007^{\star *}$ & 0.0 \\
\hline
\end{tabular}

BV, body volume; FM, fat mass; FFM, fat-free mass; TBW, total body water; Mo, bone mineral (mineral osseous). ${ }^{\star}$ Mean values at before weight loss and after weight loss were significantly different: ${ }^{*} P \leq 0.05,{ }^{\star \star} P \leq 0.001$. $\dagger \mathrm{Mo}=\mathrm{BMC} \times 1.0436$, where $\mathrm{BMC}$ is bone mineral content from dual-energy $\mathrm{X}$-ray absorptiometry. 
Table 2. Body composition parameters in the sample ( $n$ 48) at baseline, after intervention and respective differences

(Mean values and standard deviations)

\begin{tabular}{|c|c|c|c|c|c|c|}
\hline \multirow[b]{2}{*}{ Variables } & \multicolumn{2}{|c|}{ Baseline } & \multicolumn{2}{|c|}{$\begin{array}{c}\text { After } \\
\text { intervention }\end{array}$} & \multicolumn{2}{|c|}{ Difference } \\
\hline & Mean & SD & Mean & SD & Mean & SD \\
\hline \multicolumn{7}{|l|}{ FM (kg) } \\
\hline Antrform & 35.5†† & $7 \cdot 3$ & $32 \cdot 7 † \dagger$ & $7 \cdot 2$ & $-2 \cdot 8^{\star \star} \dagger$ & $2 \cdot 1$ \\
\hline BIA-Tanita & $31.4 † \dagger$ & $8 \cdot 4$ & 28.3†† & $8 \cdot 2$ & $-3 \cdot 2^{\star \star}$ & $3 \cdot 0$ \\
\hline BIA-BF300 & $29.8 \dagger \dagger$ & $7 \cdot 4$ & $26 \cdot 7 \dagger \dagger$ & $7 \cdot 5$ & $-3 \cdot 1^{\star *}$ & $2 \cdot 6$ \\
\hline DXA & $36.8 \dagger \dagger$ & $9 \cdot 4$ & $32 \cdot 3+\dagger$ & $9 \cdot 6$ & $-4 \cdot 5^{\star \star} \dagger \dagger$ & $3 \cdot 7$ \\
\hline 4-C & 32.9 & $8 \cdot 4$ & $29 \cdot 6$ & $8 \cdot 1$ & $-3 \cdot 3$ & $3 \cdot 1$ \\
\hline \multicolumn{7}{|l|}{ FM (\%) } \\
\hline Antrform & 44.5†† & $2 \cdot 4$ & 43.4†† & $2 \cdot 5$ & $-1 \cdot 1^{\star \star} \dagger$ & $0 \cdot 8$ \\
\hline BIA-Tanita & $39.4 \dagger \dagger$ & $4 \cdot 6$ & $37.3+\dagger$ & 4.9 & $-2 \cdot 1^{\star \star}$ & $2 \cdot 6$ \\
\hline BIA-BF300 & $37 \cdot 2 \dagger \dagger$ & $4 \cdot 1$ & 35.3†† & $4 \cdot 7$ & $-1 \cdot 9^{\star \star}$ & 1.9 \\
\hline DXA & $46.4 \dagger \dagger$ & $5 \cdot 8$ & $42 \cdot 7 \dagger \dagger$ & $6 \cdot 4$ & $-3 \cdot 7^{\star \star}+\dagger$ & $3 \cdot 3$ \\
\hline 4-C & $41 \cdot 1$ & $5 \cdot 2$ & $39 \cdot 1$ & $5 \cdot 3$ & $-2 \cdot 0$ & $2 \cdot 8$ \\
\hline \multicolumn{7}{|l|}{ FFM (kg) } \\
\hline Antrform & 43.7†† & $4 \cdot 7$ & $42 \cdot 1 \dagger \dagger$ & 4.9 & $-1 \cdot 6^{\star \star} \dagger$ & $1 \cdot 2$ \\
\hline BIA-Tanita & 46.9 & $3 \cdot 8$ & $46 \cdot 1 \dagger$ & $4 \cdot 2$ & $-0.8^{\star \star}$ & $1 \cdot 3$ \\
\hline BIA-BF300 & $49 \cdot 4 † \dagger$ & $5 \cdot 4$ & 48.1†† & $5 \cdot 3$ & $-1 \cdot 3^{\star \star}$ & $1 \cdot 1$ \\
\hline DXA & $41.7 \dagger \dagger$ & 4.5 & $42 \cdot 2 \dagger \dagger$ & 4.5 & $0.5^{\star}+\dagger$ & $1 \cdot 3$ \\
\hline $4-C$ & $46 \cdot 3$ & $5 \cdot 0$ & $45 \cdot 2$ & $5 \cdot 3$ & $-1 \cdot 1$ & 1.5 \\
\hline
\end{tabular}

FM, fat mass; Antrform, anthropometry (waist circumference-based model); BIATanita, bioelectrical impedance analysis using Tanita TBF-310; BIA-BF300, bioelectrical impedance analysis using Omron BF300; DXA, dual-energy X-ray absorptiometry; 4-C, four-compartment model; FFM, fat-free mass.

Mean values at baseline and after intervention were significantly different: ${ }^{*} P \leq 0.05,{ }^{*} P \leq 0.001$

Mean change was significantly different from that observed using the reference method (4-C): $\uparrow P<0.05, \dagger \dagger P<0.001$.

some of the disparities between body composition measures and the four-compartment model. The body composition changes were only significantly associated with the differences obtained between body composition variables from the fourcompartment model and DXA (hydration, FM: $\beta=-19 \cdot 3$,
$P=0.039$; FFM: $\beta=17 \cdot 0, P=0.035$; density, FM: $\beta=59 \cdot 1$, $P=0.021$; FFM: $\beta=-54 \cdot 6, P=0.013$ ). All the other differences using methods besides DXA were not associated with FFM hydration or density.

\section{Relationship between body-weight changes and differences between methods}

The relationship between the differences in FM using each method and the reference method and body-weight change is illustrated in Fig. 2. A positive correlation was found between body-weight changes and the difference between the reference four-compartment model and Antrform and DXA ( $r$ 0.418, $P<0.05$ and $r 0.386, P<0.05$, respectively). Thus, the more weight subjects lost, the greater the disparity in FM measures from Antrform and DXA and FM measures from the reference method. The difference between the methods explained $17.5 \%$ FM and $14.9 \%$ FM respectively, of total body-weight changes during the intervention. The magnitude of body-weight change did not explain the differences between FM measured from BIA-Tanita and BIA-BF300 and FM from the reference model $(P>0 \cdot 05)$.

\section{Discussion}

The primary goal of the present study was to examine the validity of clinical body composition assessment methods for measuring changes in body composition across a 16-month weight-loss intervention using a molecular four-compartment model as reference. Four-compartment models provide more accurate estimates of body composition than the other methods used to estimate body composition ${ }^{20}$, thus the present study is unique in its approach. To our knowledge, only three studies have validated measures of body composition across weight loss by comparing them with the reference

Table 3. Performance criteria: slope, intercept, coefficient of correlation, standard error of estimation and the agreement (bias, limits and trend) between fat mass (FM), percentage FM and fat-free mass (FFM) changes using the four-compartment model as the reference ( $n$ 48)

\begin{tabular}{|c|c|c|c|c|c|c|c|}
\hline \multirow[b]{2}{*}{ Variables } & \multirow[b]{2}{*}{ Slope } & \multirow[b]{2}{*}{ Intercept } & \multirow[b]{2}{*}{$r$} & \multirow[b]{2}{*}{ se of estimation } & \multicolumn{3}{|c|}{ Agreement } \\
\hline & & & & & Bias & $95 \%$ limits of agreement & Trend \\
\hline \multicolumn{8}{|l|}{ FM (kg) } \\
\hline Antrform & $1 \cdot 31 \ddagger$ & 0.38 & 0.88 & $1 \cdot 51$ & $0.5 \dagger$ & $3 \cdot 8,-2 \cdot 8$ & $-0.65^{\star \star}$ \\
\hline BIA-Tanita & 0.91 & -0.36 & 0.88 & 1.49 & 0.1 & $3 \cdot 1,-2 \cdot 9$ & -0.08 \\
\hline BIA-BF300 & 0.99 & -0.21 & 0.81 & 1.82 & 0.2 & $3 \cdot 8,-3 \cdot 4$ & $-0.31^{\star}$ \\
\hline DXA & $0.76 \ddagger$ & 0.22 & 0.90 & $1 \cdot 34$ & $-1 \cdot 2 \dagger$ & $4.5,-1.9$ & $0.37^{\star}$ \\
\hline \multicolumn{8}{|l|}{ FM (\%) } \\
\hline Antrform & $2 \cdot 27 \ddagger$ & 0.54 & 0.67 & $2 \cdot 07$ & $0.9 \dagger$ & $5 \cdot 4,-3 \cdot 7$ & $-0.90^{\star *}$ \\
\hline BIA-Tanita & $0.76 \ddagger$ & -0.36 & 0.72 & 1.94 & -0.1 & $3 \cdot 9,-4 \cdot 2$ & -0.09 \\
\hline BIA-BF300 & 0.92 & -0.18 & 0.63 & $2 \cdot 16$ & $0 \cdot 1$ & $4 \cdot 3,-4 \cdot 3$ & $-0.44^{\star}$ \\
\hline DXA & $0.67 \ddagger$ & 0.49 & 0.80 & 1.67 & $-1 \cdot 7 \dagger$ & $2 \cdot 3,-5 \cdot 7$ & $0.29^{\star}$ \\
\hline \multicolumn{8}{|l|}{ FFM (kg) } \\
\hline Antrform & $0.42 \ddagger$ & -0.46 & 0.32 & 1.48 & $-0.5 \dagger$ & $2 \cdot 8,-3 \cdot 8$ & -0.26 \\
\hline BIA-Tanita & $0.45 \ddagger$ & $-0.77 \dagger$ & 0.37 & 1.46 & 0.3 & $3.5,-2.9$ & -0.21 \\
\hline BIA-BF300 & $0.17 \ddagger$ & $-0.92 \dagger$ & 0.12 & 1.56 & -0.2 & $3 \cdot 5,-3 \cdot 8$ & $-0.31^{*}$ \\
\hline DXA & $0.66 \ddagger$ & $-1.45 \dagger$ & 0.53 & $1 \cdot 33$ & $1.6 \dagger$ & $4 \cdot 4,-1 \cdot 2$ & -0.25 \\
\hline
\end{tabular}

Antrform, anthropometry (waist circumference-based model); BIA-Tanita, bioelectrical impedance analysis using Tanita TBF-310; BIA-BF300, bioelectrical impedance analysis using Omron BF300; DXA, dual-energy X-ray absorptiometry.

Trend was significant: ${ }^{\star} P \leq 0.05,{ }^{\star} * P \leq 0.001$.

† Significantly different from 0 .

$\ddagger$ Significantly different from 1 . 

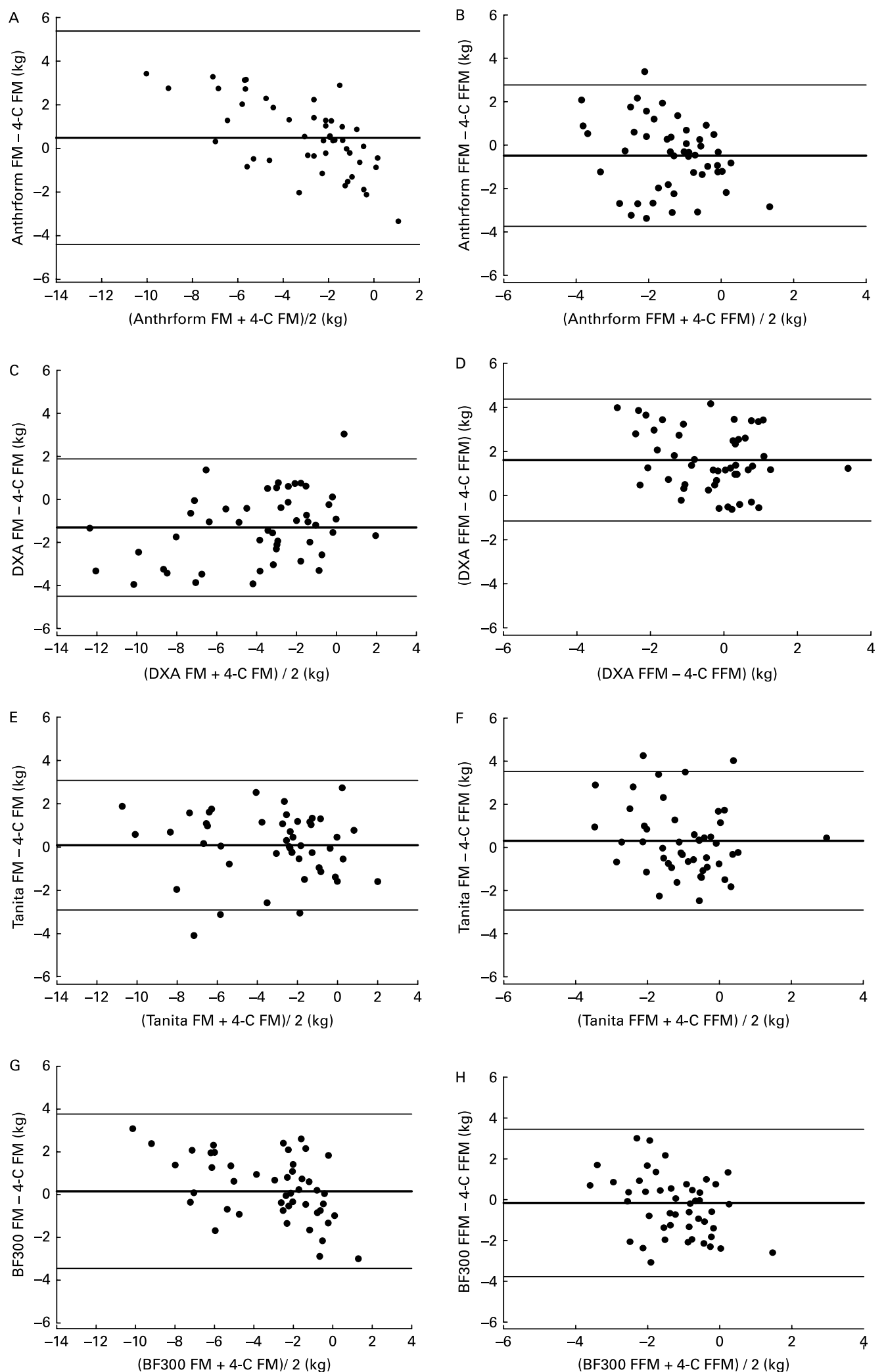

Fig. 1. Bland-Altman analysis for the change (difference between before and after weight loss) using the different methods. The middle solid line represents the mean difference between absolute fat mass (FM) (A, C, E, G) or fat-free mass (FFM) (B, D, F, H) from each method minus absolute FM or FFM from the fourcomponent model (4-C); the upper and lower dashed lines represent \pm 2 SD from the mean, i.e. $95 \%$ limits of agreement ( $\pm 1.96 \mathrm{SD})$. (A, B) Anthropometric formula (Antrform; waist circumference-based model); (C, D) dual-energy X-ray absorptiometry (DXA); (E, F) bioelectrical impedance analysis using Tanita TBF-310 (Tanita); (G, H) bioelectrical impedance analysis using Omron BF300 (BF300). 

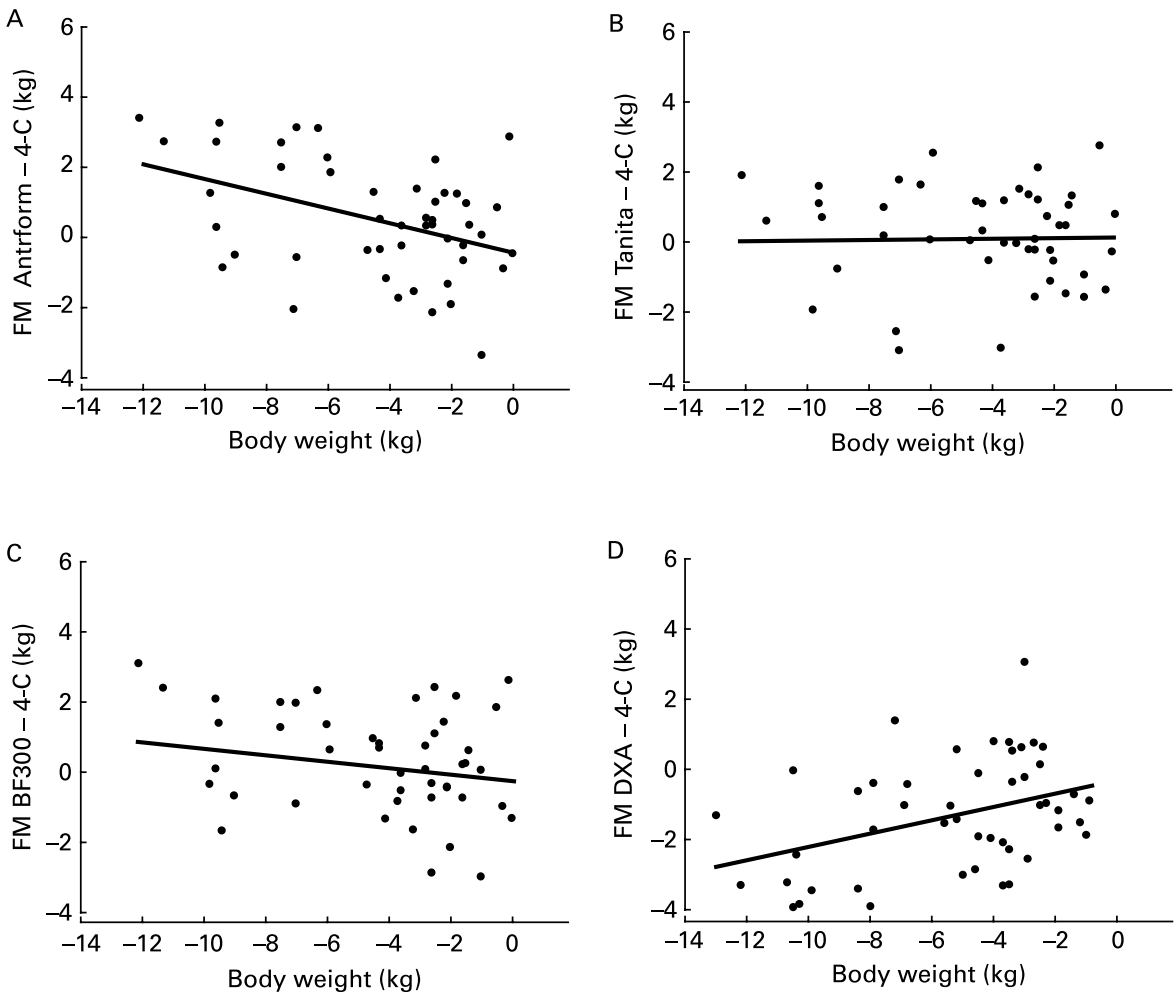

Fig. 2. Relationship between body-weight changes and the differences between methods. (A) Relationship between the difference in fat mass (FM) using anthropometry (waist circumference-based model; Antrform) and the reference method (four-compartment model; 4-C) and body-weight change; (B) relationship between the difference in FM using Tanita TBF-310 (bioelectrical impedance analysis; Tanita) and the reference method and body-weight change; (C) relationship between the difference in FM using Omron BF300 (bioelectrical impedance analysis; BF300) and the reference method and body-weight change; (D) relationship between the difference in FM using dual-energy X-ray absorptiometry (DXA) and the reference method and body-weight change.

four-compartment model ${ }^{6,8,9}$, but the present study extends these reports by including additional measures of comparison. The present findings reveal that the mean bias in estimating FM and percentage FM changes by DXA and Antrform were not similar when compared with the reference method. As in the cross-sectional data analysis, DXA overestimated FM and percentage FM change $(1.3 \mathrm{~kg}, P<0.05$ and $1.7 \%, P<0.05)$ while Antrform underestimated FM and percentage FM changes $(-0.5 \mathrm{~kg}, P<0.05$ and $-0.9 \%, P<0.05)$. The other two singlefrequency BIA devices, BIA-Tanita and BIA-BF300, similarly estimated the FM and percentage FM changes when compared with the four-compartment model.

These results extend the findings of Evans et al. ${ }^{9}$ that found no bias in percentage FM changes in the diet only and diet plus exercise weight-loss groups using BIA. Conversely, Fogelholm et al. ${ }^{6}$ found that BIA underestimated the change in FM when compared with the four-compartment model. However, in the present short-term 12-week weight-loss study, it is worth noting that, contrary to expected, FFM hydration increased from $72.9 \%$ from baseline to $75.7 \%$ after the intervention, which may explain why changes in FM and percentage FM were underestimated when compared with the reference model. Besides this methodological issue, the authors speculate that TBW may have not been detected accurately by BIA due to the expansion of the intracellular water associated with the refeeding weight-loss-stabilisation period, because the BIA method is essentially dependent on the extracellular pool.
In addition to differences in measuring the change in body composition, baseline measures of FM and percentage FM by Antrform, BIA-Tanita, BIA-BF300 and DXA were not similar to the reference model. Antrform and DXA overestimated FM and percentage FM while BIA-Tanita and BIA-BF300 underestimated FM and percentage FM. Similar results were found after the intervention. Before weight loss, FFM hydration in the present study was $76.2 \%$, demonstrating an overhydrated state as was expected in overweight and obese individuals ${ }^{7}$. After weight loss, FFM hydration changed to $74.4 \%$. It is important to note that before weight loss FFM hydration was significantly higher than the assumed hydration status $(73.8 \%)$ based on chemical cadaver analysis ${ }^{21}$. These results indicate that women in the present study may have been overly hydrated, which would result in an overestimation of FFM before weight loss by using BIA-based methods. Indeed, the present results extend the results found by Frisard et $a l^{22}$ and Carella et $a l^{23}$ and are in agreement with the knowledge that there is large variation in the water content of $\mathrm{FFM}^{24}$, and that these differences can lead to an underestimation of FFM with BIA in the dehydrated state and an overestimation in the overhydrated state ${ }^{25}$. These findings may explain the significant increase in the $\mathrm{D}_{\mathrm{FFM}}$ after weight loss. No differences were found between $D_{\mathrm{FFM}}$ observed and the assumed $D_{F F M}\left(1 \cdot 1 \mathrm{~g} / \mathrm{cm}^{3}\right)$ after weight loss, while the baseline values were significantly lower.

As extensively documented, the pencil-beam DXA technology used in the present study (Hologic QDR-1500W with 
enhanced software version 5.71) tends to overestimate $\mathrm{FM}^{9,26}$. Williams et $a .^{27}$, using a fan-beam technology, also suggested an average higher error in obese subjects. We also found this trend. As compared with the four-compartment model, at baseline when subjects were fatter, DXA overestimated FM by $3.9 \mathrm{~kg}$, while after weight loss this difference decreased to $2.7 \mathrm{~kg}$. It has been suggested that 'beam hardening' due to increased body tissue thickness may explain these differences $^{28}$. New fan-beam technology and algorithms have already improved DXA accuracy to estimate $\mathrm{FM}^{29,30}$. The highest correlation coefficient between body composition changes was found for DXA.

The slopes and intercepts for FM and percentage FM changes with the two BIA methods were not different from 1 and 0 , respectively, when the four-compartment model was used as the reference. This would indicate a good accuracy for BIA-Tanita and BIA-BF300. However, considering the data from the agreement analysis, both methods had a wide range for the $95 \% \mathrm{CI}$, indicating a reduced individual accuracy. Further, a significant trend, i.e. a significant correlation between the mean changes observed between BF300 and the four-compartment model and the difference between both methods was found. In other words, the fact that there were not differences between mean FM and percentage FM changes estimated by the four-compartment model and BIABF300 is most likely because BIA-BF300 overestimated in subjects that lost less FM and underestimated in subjects that lost more FM. This result underscores the notion that BIA-BF300 is not sensitive to track accurately individuals across large changes in body composition.

Results using the Antrform method are in line with the recognition that it is very difficult for anthropometric methods to accurately estimate body composition changes ${ }^{31}$. Besides the significant mean bias found for FM and percentage FM changes with DXA, this method also presented a significant trend in the opposite direction. DXA overestimated FM loss in subjects that lost more FM. This finding agrees with previous findings that DXA is less accurate in subjects with larger $\mathrm{FM}^{27}$. As depicted in Fig. 1, this was further emphasised by the finding that body-weight changes explained $17.5 \%$ of the difference between the methods. Comparable but opposite results were found with Antrform. Differences between FM changes with the BIA devices and the four-compartment model were not associated with the body-weight changes. Thus, the estimated changes are not dependent of the amount of body weight loss.

The effects of the FFM hydration and $\mathrm{D}_{\mathrm{FFM}}$ on body composition differences observed using the several methods and the four-compartment model were also investigated. The findings showed that there were no associations between changes in FFM hydration and the disparities between the test body composition measures and the four-compartment model, with the exception of DXA (hydration: $\beta=-19.26$, $P=0.039$; density: $\beta=59.05, P=0.021$ ). Our findings are consistent with those obtained by Kohrt ${ }^{32}$ that found no influence of FFM hydration changes on assessing small changes of body composition.

Early work showed that the high precision of DXA for estimation of body composition components provided the technology to detect very small changes in body composition ${ }^{33}$. Studies in haemodialysis patients and healthy adults have shown that DXA accurately assessed acute changes in soft tissue $^{34,35}$. DXA also appears to be a suitable method for assessing body composition changes in longitudinal studies $^{22,36}$. It is important to note that the conclusions regarding DXA's ability to correctly assess FM and percentage FM may not be applicable to the equipment used in the present investigation, as known significant differences exist between manufacturers and software 32,37 .

Although the above findings are based on the assumption that differences between clinical estimates of FM and percentage FM from the reference four-compartment model resulted from error in the alternative method estimation, absolute FM from the reference model is not without error. It has been suggested that the increased error associated with the greater number of measurements contributing to FM estimation with the four-compartment model may negate its greater theoretical accuracy $^{38}$. The present investigation and the results from Friedl et $a l_{.}{ }^{39}$ found, however, that the within-subject SD for replicate measurements FM is low ( $<0.8 \%$ of body weight) and similar to that derived with other indirect methods based on fewer measurements, indicating that propagation of measurement error is not a significant problem. For example, the SE of estimation for predicting changes in percentage FM from the reference method from changes in percentage FM from DXA, BIA-Tanita, Antrform and BIA-BF300 were 1.7 , $1.9,2.1$ and $2.2 \%$ of body weight, respectively, for an average SE of estimation of about $2.0 \%$ of body weight for the clinical methods. With the use of the law of propagation of errors and assuming that the criterion measure is not error free (total error of estimation for percentage FM of the four-compartment model: $0.8 \%$ of body weight), the proportion of the SE of estimation attributable to the clinical method is reduced to $1.8 \%$ of body weight. To detect a true change in percentage FM from a weight loss in $95 \%$ of individuals, percentage FM would have to change by $\geq 3.2 \%$. Because the propagation of measurement error is nearly $0.8 \%$ and the mean percentage FM change obtained by the reference method is $2.0 \%$, the present study agrees with other authors that highlight the difficulty in accurately assessing small changes in body composition with clinical methods ${ }^{9,40}$.

When interpreting the results from the present study the following limitations need consideration. First, our sample did not include severely obese women and the sample on average did not lose much weight. Second, the present study used bioelectrical impedance spectroscopy to estimate TBW. A correlation coefficient of 0.96 between bioelectrical impedance spectroscopy and a dilution method has been reported $^{41}$. In results from our laboratory (AM Silva et al. unpublished results) we found that estimations of TBW using isotopic MS and ${ }^{2} \mathrm{H}$ are highly correlated ( $r$ 0.92). Even though these high correlation coefficients were found between bioelectrical impedance spectroscopy and ${ }^{2} \mathrm{H}$ dilution, one should consider that these two methods may yield limits of agreement that are close to $5 \%$. However, considering the four-compartment model used in the present study, this results in an error of $\pm 1.2 \mathrm{~kg}$ of FM based on a four-compartment model. Regardless, the use of a four-compartment model in the present study must be considered as a major strength. Other strengths include the validity assessment of a wide variety of alternative clinical and field methods to track body composition changes. 


\section{Conclusion}

The findings of the present study highlight the fact that methods widely used in clinical settings should not be applied interchangeably to detect body composition changes after a weight-loss management programme. In conclusion, the results suggest that errors in body composition changes with weight loss assessed by DXA, BIA-Tanita, BF-300 and Antrform are similar when compared with a four-compartment model, though BIA-Tanita estimates of mean changes in body composition were unbiased when compared with the other clinical methods. Overall, a similar potential for individual accuracy was found in the detection of FM changes. However, DXA presented a better performance in predicting mean FFM changes from the reference model in comparison with the other methods. Furthermore, given the relatively larger average error of prediction with the techniques used in the present study, small physiological changes in body composition may not be accurately detected by these clinical methods after a weight-loss intervention.

\section{Acknowledgements}

The present study was supported by the Portuguese Foundation for Science and Technology.

\section{References}

1. Baumgartner RN, Heymsfield SB, Lichtman S, Wang J \& Pierson JN Jr (1991) Body composition in elderly people: effect of criterion estimates on predictive equations. Am $J$ Clin Nutr 53, 1345-1353.

2. Heymsfield SB \& Waki M (1991) Body composition in humans: advances in the development of multicompartment chemical models. Nutr Rev 49, 97-108.

3. Fogelholm M \& van Marken Lichtenbelt W (1997) Comparison of body composition methods: a literature analysis. Eur J Clin Nutr 51, 495-503.

4. Siri WE (1961) Body composition from fluid spaces and density: analysis of method. In Techniques for Measuring Body Composition, pp. 223-244 [A Henschel, editor]. Washington, DC: National Academy of Sciences.

5. Heymsfield SB, Lohman TG, Wang ZM \& Going SB (2005) Human Body Composition, 2nd ed. Champaign, IL: Human Kinetics.

6. Fogelholm GM, Sievanen HT, van Marken Lichtenbelt WD \& Westerterp KR (1997) Assessment of fat-mass loss during weight reduction in obese women. Metabolism 46, 968-975.

7. Leone PA, Gallagher D, Wang J \& Heymsfield SB (2000) Relative overhydration of fat-free mass in postobese versus neverobese subjects. Ann N Y Acad Sci 904, 514-519.

8. Albu J, Smolowitz J, Lichtman S, Heymsfield SB, Wang J, Pierson RN Jr \& Pi-Sunyer FX (1992) Composition of weight loss in severely obese women: a new look at old methods. Metabolism 41, 1068-1074.

9. Evans EM, Saunders MJ, Spano MA, Arngrimsson SA, Lewis RD \& Cureton KJ (1999) Body-composition changes with diet and exercise in obese women: a comparison of estimates from clinical methods and a 4-component model. Am J Clin Nutr 70, 5-12.

10. Teixeira PJ, Going SB, Houtkooper LB, Cussler EC, Metcalfe LL, Blew RM, Sardinha LB \& Lohman TG (2004) Pretreatment predictors of attrition and successful weight management in women. Int J Obes Relat Metab Disord 28, 1124-1133.

11. Weltman A, Levine S, Seip RL \& Tran ZV (1988) Accurate assessment of body composition in obese females. Am J Clin Nutr 48, 1179-1183.

12. Harrison GG, Buskirk ER, Lindsay Carter JE, Johnston FE, Lohman TG, Pollock ML, Roche AF \& Wilmore JH (1988) Skinfold thickness and measurement technique, pp. 55-70. In Anthropometric Standardization Reference Manual [TG Lohman, AF Roche and R Martorell, editors]. Champaign, IL: Human Kinetics.

13. McCrory MA, Gomez TD, Bernauer EM \& Mole PA (1995) Evaluation of a new air displacement plethysmograph for measuring human body composition. Med Sci Sports Exerc 27, 1686-1691.

14. Dempster P \& Aitkens S (1995) A new air displacement method for the determination of human body composition. Med Sci Sports Exerc 27, 1692-1697.

15. Dubois AB, Botelho SY, Bedell GN, Marshall R \& Comroe JH Jr (1956) A rapid plethysmographic method for measuring thoracic gas volume: a comparison with a nitrogen washout method for measuring functional residual capacity in normal subjects. J Clin Invest 35, 322-326.

16. Cole KS \& Cole RH (1941) Dispersion and absorption in dielectrics. J Chem Physiol 9, 341-351.

17. Hanai T (1968) Electrical properties of emulsions. In Emulsion Science, pp. 354-477 [P Sherman, editor]. New York: Academic Press.

18. Ballor DL (1996) Exercise training and body composition changes. In Human Body Composition, pp. 287-304 [TG Lohman, editor]. Champaign, IL: Human Kinetics Publishers.

19. Bland JM \& Altman DG (1986) Statistical methods for assessing agreement between two methods for clinical measurement. Lancet 8, 307-310.

20. Lohman TG (1986) Applicability of body composition techniques and constants for children and youths. Exerc Sport Sci Rev 14, 325-357.

21. Brozek J, Grande F, Anderson JT \& Keys A (1963) Densitometric analysis of body composition: revision of some quantitative assumptions. Ann N Y Acad Sci 110, 113-140.

22. Frisard MI, Greenway FL \& Delany JP (2005) Comparison of methods to assess body composition changes during a period of weight loss. Obes Res 13, 845-854.

23. Carella MJ, Rodgers CD, Anderson D \& Gossain VV (1997) Serial measurements of body composition in obese subjects during a very-low-energy diet (VLED) comparing bioelectrical impedance with hydrodensitometry. Obes Res 5, 250-256.

24. Hewitt MJ, Going SB, Williams DP \& Lohman TG (1993) Hydration of the fat-free body mass in children and adults: implications for body composition assessment. Am J Physiol 265, E88-E95.

25. de Fijter CW, de Fijter MM, Oe LP, Donker AJ \& de Vries PM (1993) The impact of hydration status on the assessment of lean body mass by body electrical impedance in dialysis patients. Adv Perit Dial 9, 101-104.

26. Lohman TG, Harris M, Teixeira PJ \& Weiss L (2006) Assessing body composition and changes in body composition. Another look at dualenergy X-ray absorptiometry. Ann N Y Acad Sci 904, 45-54.

27. Williams JE, Wells JC, Wilson CM, Haroun D, Lucas A \& Fewtrell MS (2006) Evaluation of Lunar Prodigy dual-energy $\mathrm{X}$-ray absorptiometry for assessing body composition in healthy persons and patients by comparison with the criterion 4-component model. Am J Clin Nutr 83, 1047-1054.

28. Blake GM, McKeeney DB, Chhaya SC, Ryan PJ \& Fogelman I (1992) Dual energy X-ray absorptiometry: the effects of beam hardening on bone density measurements. Med Phys 19, $459-465$. 
29. Tylavsky FA, Fuerst T, Nevitt M, Dockrell M, Wan JY, Cauley J \& Harris T (2000) Measurement of changes in soft tissue mass and fat mass with weight change: pencil- versus fan-beam dualenergy X-ray absorptiometry. Health ABC Study. Ann N Y Acad Sci 904, 94-97.

30. Visser M, Fuerst T, Lang T, Salamone L \& Harris TB (1999) Validity of fan-beam dual-energy X-ray absorptiometry for measuring fat-free mass and leg muscle mass. Health, Aging, and Body Composition Study - Dual-Energy X-ray Absorptiometry and Body Composition Working Group. J Appl Physiol 87, 1513-1520.

31. Bellisari AR \& Roche AF (2005) Anthropometry and ultrasound. In Human Body Composition, pp. 109-127 [SB Heymsfield, TG Lohman, ZM Wang and SB Going, editors]. Champaign, IL: Human Kinetics Publishers.

32. Kohrt WM (1998) Preliminary evidence that DEXA provides an accurate assessment of body composition. J Appl Physiol 84, 372-377.

33. Heymsfield SB, Wang J, Lichtman S, Kamen Y, Kehayias J \& Pierson RN Jr (1989) Body composition in elderly subjects: a critical appraisal of clinical methodology. Am J Clin Nutr 50, Suppl. 5, 1167-1175, discussion 1231-1235.

34. Stenver DI, Gotfredsen A, Hilsted J \& Nielsen B (1995) Body composition in hemodialysis patients measured by dual-energy X-ray absorptiometry. Am J Nephrol 15, 105-110.

35. Formica C, Atkinson MG, Nyulasi I, McKay J, Heale W \& Seeman E (1993) Body composition following hemodialysis: studies using dual-energy X-ray absorptiometry and bioelectrical impedance analysis. Osteoporos Int 3, 192-197.

36. Svendson OL (1996) Body composition and fat distribution by dual energy X-ray absorptiometry in overweight postmenopausal women. Effect of energy-restriction and exercise. Dan Med Bull 43, 249-262.

37. Van Loan MD, Keim NL, Berg K \& Mayclin PL (1995) Evaluation of body composition by dual energy X-ray absorptiometry and two different software packages. Med Sci Sports Exerc 27, 587-591.

38. Fuller NJ, Jebb SA, Laskey MA, Coward WA \& Elia M (1992) Four-component model for the assessment of body composition in humans: comparison with alternative methods, and evaluation of the density and hydration of fat-free mass. Clin Sci (Lond) 82, 687-693.

39. Friedl KE, DeLuca JP, Marchitelli LJ \& Vogel JA (1992) Reliability of body-fat estimations from a four-compartment model by using density, body water, and bone mineral measurements. Am J Clin Nutr 55, 764-770.

40. Lohman TG (1984) Research progress in validation of laboratory methods of assessing body composition. Med Sci Sports Exerc 16, 596-605.

41. Matthie J, Zarowitz B, De Lorenzo A, Andreoli A, Katzarski K, Pan G \& Withers P (1998) Analytic assessment of the various bioimpedance methods used to estimate body water. J Appl Physiol 84, 1801-1816. 